\title{
Clinical features of Guillain-Barré syndrome patients with elevated serum creatine kinase levels
}

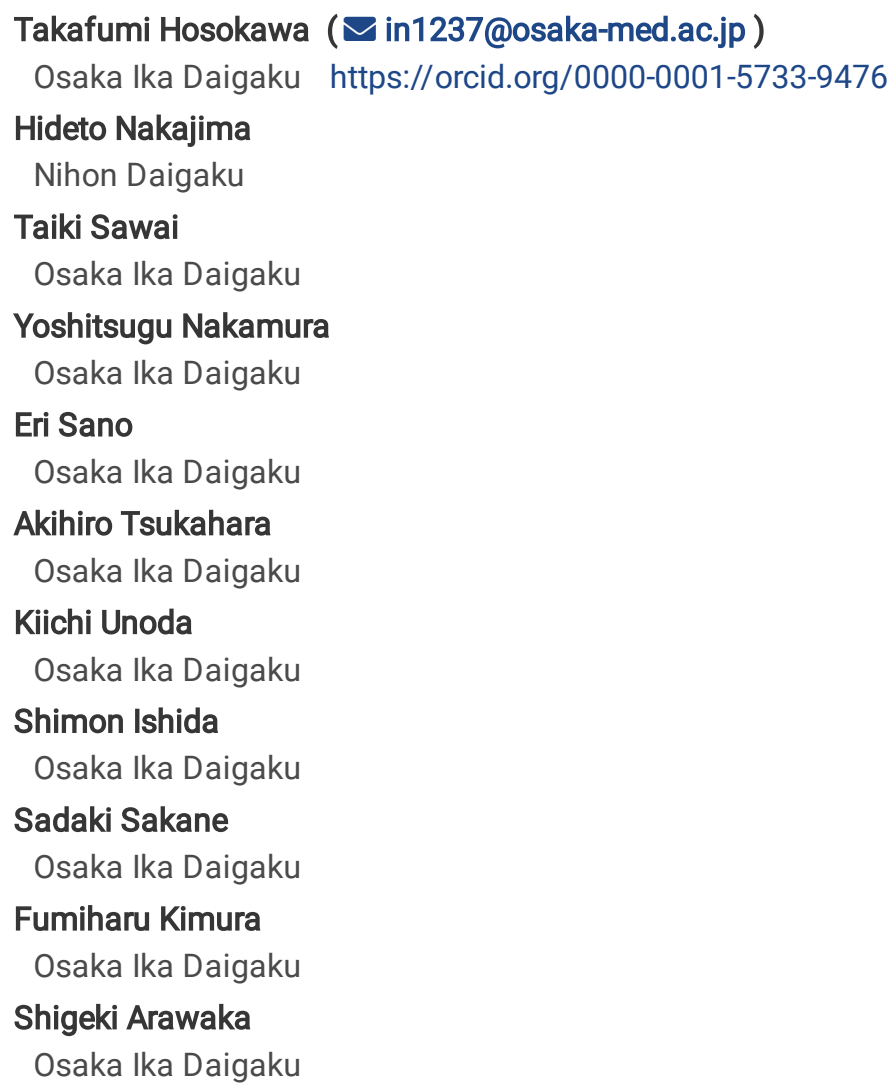

Research article

Keywords: Creatine kinase, Guillain-Barré syndrome, AIDP, AMAN, reversible conduction failure

Posted Date: May 14th, 2020

DOI: https://doi.org/10.21203/rs.2.23069/v2

License: @ (1) This work is licensed under a Creative Commons Attribution 4.0 International License. Read Full License

Version of Record: A version of this preprint was published at BMC Neurology on May 27th, 2020. See the published version at https://doi.org/10.1186/s12883-020-01796-z. 


\section{Abstract}

Background: It is not well defined whether Guillain-Barré syndrome (GBS) patients with elevated serum creatine kinase (CK) levels have characteristic clinical features and are related to the subgroups of GBS.

Methods: We retrospectively studied 51 consecutive patients with GBS, who visited our hospital, and compared clinical, laboratory and electrophysiological findings between patients with and without elevated CK levels.

Results: Of 51 patients, 14 patients (27\%) showed an elevation of serum CK levels. When compared with patients with the normal CK levels, the ratios of male, antecedent infections, and anti-GM1 antibody positivity were significantly higher in patients with elevated CK levels. The ratios of hypoesthesia, cranial nerve involvement, and urinary retention were significantly less in patients with elevated CK levels. There were no significant differences in disability at peak between two groups. In the electrophysiological examination, sensory nerve abnormalities were not observed. Although some patients with elevated CK levels showed prolongation of distal motor latencies (DMLs) and increase of durations in the initial examination, development of the prolongation of DMLs and increase of durations was not observed in the follow-up examinations. The findings were consistent with acute motor axonal neuropathy (AMAN) with reversible conduction failure (RCF) but not acute inflammatory demyelinating polyneuropathy (AIDP).

Conclusions: The results suggest that the GBS patients with elevated CK levels represent not a group of AIDP but a group of AMAN with axonal degeneration or RCF even though the initial electrophysiological examination shows AIDP pattern.

\section{Introduction}

While cerebrospinal fluid test abnormalities in Guillain-Barré syndrome (GBS) are well known, serum test abnormalities have also been reported. One such serum abnormality in GBS is an elevation in creatine kinase (CK) levels;[1] however, it is unclear whether GBS with elevated CK levels has homogeneous features, and if so, what those features are. Especially, association of GBS with elevated CK levels and GBS subgroup is unclear. One of the reasons may be the difficulty and confusion to clinically diagnose GBS subgroups including acute motor axonal neuropathy (AMAN) with reversible conduction failure (RCF).

GBS is classified into two major subgroups: acute inflammatory demyelinating polyneuropathy (AIDP) and AMAN.[2-7] AMAN is further classified into the subgroups, such as AMAN with axonal degeneration and RCF.[8] AMAN with RCF is characterized clinically by rapid improvement. $[6,9,10]$ It is important to accurately diagnose the subgroups in patients with GBS for predicting the therapeutic responsiveness.

Although these subgroups are clinically diagnosed by electrophysiological findings, conventional examinations are reported to be often inconsistent with the true subgroup of GBS. $11-41 \%$ of patients with GBS failed to judge AIDP or AMAN, because electrophysiological findings did not fulfill the criteria for AIDP or AMAN patterns.[2, 11-13] Additionally, AMAN with RCF is misdiagnosed as AIDP, because electrophysiological examinations at the acute phase indicate the AIDP pattern, such as prolongation of distal motor latencies (DMLs) and increase of durations.[11,12,14] This means that the AIDP pattern on electrophysiological examinations reflects two different subgroups, AIDP and AMAN with RCF. However, previous reports demonstrated that the follow-up electrophysiological examinations are useful for resolving this issue: $[12,13,15]$ AMAN with RCF shows rapid improvement of the AIDP pattern, $[8,9,11,13]$ whereas true AIDP shows development of these abnormalities.[16, 17] Moreover, we previously reported that AMAN with RCF did not show sensory nerve conduction abnormalities in contrast to true AIDP.[18] . We also demonstrated that the true disease subgroup of "AMAN pattern" and unclassified GBS is AMAN with axonal degeneration and AMAN with RCF, respectively.[18, 19] Using these findings, we established the method to classifying GBS into AMAN with axonal degeneration, AMAN with RCF, and true AIDP. While a limited number of patients undergo serial electrophysiological examinations and analysis using the serial examination can have biased effect, the analysis using our classification requires only a single electrophysiological examination for almost all GBS patients.

In this study, we focused on the GBS patients with elevated CK levels. We investigated whether these patients are related to the specific subgroups of GBS by performing repeat electrophysiological examinations.

\section{Material And Methods}

\section{Patients}


We retrospectively evaluated 51 consecutive GBS patients who visited Osaka Medical College Hospital from January 2005 to December 2016 (31 men, 20 women; mean age 45.9 years, range 17 - 80 years). These patients underwent initial nerve conduction examinations within 17 days of onset. All patients fulfilled the clinical criteria for GBS,[20] except the point regarding areflexia or hyporeflexia. We enrolled these patients, because the presence of GBS patients with normal or exaggerated tendon reflexes was shown previously.[9, 21] Three GBS patients were excluded from this study, because these patients had diabetic neuropathy and it was difficult to appropriately separate abnormalities in the sensory nerve conduction by GBS from those by diabetic neuropathy.

Patient disabilities were evaluated according to the Hughes disability grade scale as follows: grade 0 , healthy; grade 1 , minor signs and symptoms, able to run; grade 2, able to walk independently; grade 3, able to walk with a walker or support; grade 4, bed or chair bound; grade 5, assisted respiration required for at least part of the day; and grade 6, dead.[22] Elevation of serum CK levels was defined as the values $>200 \mathrm{U} / \mathrm{L}$ (normal range 30-200 U/L) for more than 3 days during 4 weeks after onset. The reason why we required the duration of CK elevation to be more than 3 days is to exclude the influence of non-pathogenic conditions. Although non-pathogenic conditions such as physical exercise are known to cause temporal CK elevation, a large community study found that repeat CK levels in people with incidentally discovered elevated CK were normal after 3 days of rest in $70 \%$ of cases.[23] The reason why determination of CK elevation was based on CK levels during 4 weeks after onset is to minimize bias caused by different observation time, as almost all patients underwent laboratory tests during 4 weeks after onset at least. CK levels were measured before electromyographic examination, if it was performed.

\section{Electrophysiological examinations}

Motor and sensory nerve conduction examinations were performed using MEB-9104 Neuropack mu® (Nihon Kohden, Japan) according to the methods and reference values as described by Kimura et al.[24] Motor nerve conduction examinations were performed on the median, ulnar, peroneal, and tibial nerves. Compound action potential (CMAP) duration was defined as the time from the onset of the initial negative phase until the last negative deflection of CMAP returned to the baseline. Antidromic sensory nerve conduction examinations were performed on the median, ulnar, and sural nerves. Based on the results of initial electrophysiological examinations, patients were classified into the AIDP or AMAN pattern according to the criteria of Ho et al.[2] Although their criteria set includes unequivocal temporal dispersion for the detection of demyelination, how much temporal dispersion of CMAP should be considered as "unequivocal" one is not defined in the criteria. Therefore, we used a distal CMAP duration $>6.6 \mathrm{~ms}$ in the median, $>6.7 \mathrm{~ms}$ in the ulnar, > $7.6 \mathrm{~ms}$ in the peroneal, and $>8.8 \mathrm{~ms}$ in the tibial nerves[25] or $>30 \%$ increase in duration ratio of the proximal CMAP to distal one in all nerves.[26] When the electrophysiological findings did not fulfill the criteria for AIDP or AMAN patterns, the patients were designated as unclassified GBS. The absence of $F$ waves was defined as the absence or marked decrease (persistence $<20 \%$ ) of $F$ waves in at least two nerves.[27] Patients were considered to have sensory nerve conduction abnormalities when the sensory nerve action potential amplitude was $<50 \%$ of the lower limit of normal range in at least two nerves.[28] In this study, the electrophysiological patterns of AIDP and AMAN were expressed as the "AIDP pattern" and the "AMAN pattern", respectively.

\section{Subgroup definitions}

In accordance with our previous findings as mentioned above,[18, 19] AIDP was defined as electrodiagnosis of "AIDP pattern" with sensory nerve conduction abnormalities based on Ho's criteria. AMAN with axonal degeneration was defined as electrodiagnosis of "AMAN pattern". AMAN with RCF was defined as electrodiagnosis of "AIDP pattern" without sensory nerve conduction abnormalities or unclassified.

\section{Statistical analyses}

Differences in mean values between two groups were analyzed using the Mann-Whitney $U$ test, and differences in frequencies were analyzed using the Fisher exact probability test. Time to event was analyzed by the Kaplan-Meier method and the log-rank test for trend. Statistical significance was set at $P<0.05$. All analyses were performed using GraphPad PRISM version 5.01 (GraphPad Software, San Diego, CA, USA). 


\section{Results}

\section{Clinical and laboratory features of GBS patients with elevated CK levels}

Table 1 shows a comparison of clinical and laboratory findings of GBS patients with and without elevated CK levels. Of 51 patients, 14 (27\%) patients showed an elevation of serum CK levels and 37 (73\%) patients showed normal CK levels. The ratio of male in patients with elevated CK levels $(n=12)$ were significantly higher than that of patients with normal CK levels $(n=19, P=0.029)$. The incidence of infections prior to the onset of GBS in patients with elevated CK levels $(n=13)$ were significantly higher than that of patients with normal CK levels $(n=22, P=0.039)$. As antecedent infections, the ratio of upper respiratory tract infection in patients with elevated CK levels $(n=8)$ were higher than that of patients with normal CK levels $(n=8, P=0.021)$. Anti-GM1 antibody was measured in 12 and 32 patients with and without elevated CK levels, respectively. The positive ratio of anti-GM1 antibody in patients with elevated CK levels $(n=8)$ were higher than that in patients with normal CK levels $(n=8, P=0.016)$. The incidences of hypoesthesia and cranial nerve involvement in patients with elevated CK levels ( $n=1$ and 2, respectively) were significantly less than those in patients with normal CK levels ( $n=15$ and 19 , respectively, $P=0.016)$. Patients with elevated $C K$ levels showed no urinary retention. There were no significant differences in disability at peak between two groups. Moreover, there were no significant differences in time to Hugh grade 1 between two groups (data was not shown).

\section{The electrophysiological features at the initial examinations}

Based on the initial electrophysiological findings, 51 patients were classified as having the "AIDP pattern" ( $n=30,59 \%$ ), the "AMAN pattern" ( $n=8,16 \%)$, and electrophysiologically unclassified $(n=13,25 \%)$. One patient with the "AMAN pattern" with normal CK levels showed sensory nerve conduction abnormalities, indicating the "acute motor and sensory axonal neuropathy pattern" in the strict sense. [29] Table 2 shows findings in the initial electrophysiological examinations. Although, in patients with elevated CK levels, one patient with the "AMAN pattern" showed hypoesthesia, electrophysiological criteria of sensory nerve abnormality were not fulfilled. There were no GBS patients with elevated CK levels clearly having sensory nerve conduction abnormalities. Subgroups of GBS patients with elevated CK levels

Table 3 shows subgroups of GBS patients with and without elevated CK levels. All GBS patients with elevated CK levels were diagnosed as AMAN with axonal degeneration or RCF. In contrast, $>40 \%$ of GBS patients with normal CK levels were diagnosed as AIDP. The ratio of AMAN following upper respiratory tract infection (URTI) in patients with elevated CK levels $(n=8,2$ with axonal degeneration and 6 with RCF) were significantly higher than that of patients with normal CK levels ( $n=4,2$ with axonal degeneration and 2 with RCF, $P=0.0014$ ). Of patients with AMAN following URTI, 5 patients with elevated CK levels ( 2 with axonal degeneration and 3 with RCF) and 1 patient with normal CK levels (1 with RCF) were positive for anti-GM1 antibody. Table 4 shows serum CK levels and clinical course of 14 patients with elevated CK levels. To anonymize the identifying information, specific ages were grouped into age ranges. None of the 14 patients with elevated CK levels were taking statin. CK values were not significantly correlated with disability grades or CMAP amplitudes. In most of GBS patients with elevated CK levels, elevation of CK began within 2 weeks, and peak of CK followed nadir of disability within 2 weeks.

\section{The electrophysiological features at the follow-up examinations}

Of 14 patients with elevated CK levels, 12 patients underwent follow-up electrophysiological examinations. Of 37 patients with normal CK levels, 22 patients underwent follow-up electrophysiological examinations. Fig. 1 shows temporal changes of electrophysiological parameters at the right median nerve. Some GBS patients with elevated CK levels showed prolongation of DMLs and increase of durations in the initial examinations. However, none showed development of increased durations and prolonged DMLs in the follow-up examinations, while some GBS patients with normal CK levels did show development.

\section{Discussion}

The present study shows that the elevation of CK levels is seen in GBS. $27 \%$ of patients had the elevation of CK levels in the first 4 weeks after onset. In this study, our classification discovers that all GBS patients with elevated CK levels represent a group of AMAN with axonal degeneration or RCF. Moreover, while a limited number of patients underwent serial electrophysiological examinations, serial examinations also confirmed that GBS with elevated CK levels is AMAN with axonal degeneration or RCF, not a group of AIDP. In the initial electrophysiological examinations, some GBS patients with elevated CK levels were classified as the "AIDP pattern" based on Ho's criteria, which showed prolongation of DMLs and increase in durations. However, they showed small extent of demyelinating features, 
which is consistent with RCF in the first place. $[11,12,14]$ Notably, in the follow-up examinations, they showed electrophysiological

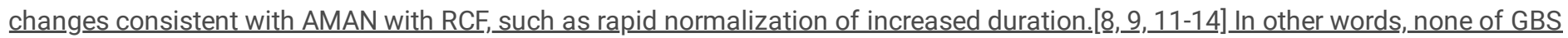
patients with elevated CK levels showed changes consistent with true AIDP, such as the development of this prolongation of DMLs and increase of durations in. On the other hand, it was seen in some GBS patients with normal CK levels, suggesting that GBS with normal CK levels includes true AIDP.

Several features of GBS patients with elevated CK levels other than electrophysiological findings also confirm that GBS patients with elevated CK levels represent a group of AMAN. In our study, patients with elevated CK levels frequently had antecedent infections and anti-GM1 antibody, rarely had hypoesthesia and cranial nerve involvement, and did not have urinary retention as signs of autonomic failure; all of the features were consistent with AMAN and not true AIDP.[2, 4-6] Conversely, while the most common antecedent infection in AMAN was gastroenteritis, particularly from Campylobacter jejuni, the most common antecedent infection in GBS patients with elevated CK levels in this study was URTI. Subsequently, in GBS patients with elevated CK levels, there were some with AMAN with antiGM1 antibody following URTI, while anti-GM1 antibody is usually related not with URTI but with gastroenteritis such as C.jejuni infection. AMAN following URTI, including with anti-GM1 antibody, may be a specific feature of GBS patients with elevated CK levels.

To our knowledge, while we found some case reports of GBS patients with elevated CK levels, $[1,30,31]$ there is only one report of a series of GBS patients in whom CK levels was investigated.[32] That report showed a 52\% incidence of the elevation of CK levels in GBS and pain associated with the elevation of CK levels in GBS patients; however, the authors did not record the disease subgroup of GBS and consequently did not mention the correlation between GBS disease subgroup and the elevation of CK levels. Therefore, our study is the first study of a series of GBS patients in whom correlation between GBS disease subgroup and elevation of CK levels is investigated, demonstrating that GBS patients with elevated CK levels represent a group of AMAN.

Although the mechanism of elevation of CK levels in GBS is still uncertain, several possible mechanisms were proposed in the literature. One possible mechanism is associated with rhabdomyolysis caused by antecedent infection.[30] This mechanism, however, is unlikely because the patients with rhabdomyolysis showed markedly raised CK levels, which were not consistent with our cases with moderate raised CK levels. Another possible mechanism is that rapid denervation due to axonal damage can result in the release of muscle enzymes.[1] It is also proposed that CK elevation could be caused by painful muscle cramp associated with active denervation on the basis of the finding that most of GBS patients with elevated CK levels developed painful sensation. Regrettably, we could not investigate the association between elevation of CK levels and pain, because of retrospective nature of our study. However, the mechanism that denervation could cause CK elevation is consistent with our observation that elevation of CK levels occurred in AMAN with RCF as well as AMAN with axonal degeneration but not in AIDP, because the denervation could occur in AMAN with RCF as well as AMAN with axonal degeneration but not in demyelination alone.[33,34] The mechanism could explain our observations that elevation of CK began within 2 weeks after onset and that peak of CK followed nadir of disability within 2 weeks, because denervation follows axonal degeneration within at most 2 weeks in proportion to the distance of the muscle from the injury site. The mechanism could also explain that in some of our patients, the elevation of CK levels occurred within a few days, because motor nerve terminal located a bit distant from muscle is preferentially affected at first in GBS. Moreover, given that not all AMAN patients showed CK elevation, a specific mechanism other than those directly caused by axonal damage may also be necessary for CK elevation. Mentioned above, we found that AMAN following URTI, including with anti-GM1 antibody, may be a specific feature of GBS patients with elevated CK levels. Although we could not investigate the antecedent pathogens, AMAN following URTI, including with anti-GM1 antibody, was reportedly associated with a specific pathogen such as Haemophilus influenzae.[35] Therefore, the specific pathogen not identified in this study may elicit not only URTI and subsequent AMAN but also additional mechanisms that are specific to elevation of CK levels.

Our study has several limitations. First, it is small and retrospective and includes only patients from Japan, where AMAN patients are more frequent than other Western countries. Further large prospective studies in various population groups are needed. Second, although serial electrophysiological examinations were performed, the number of nerves, timing, frequency, and period varied for each patient. In some patients, serial examinations were performed only a few times over a short period or not performed at all. Of nerve conduction examinations on any motor nerves, that on the right median nerve was most often performed in our study. Therefore, we only showed the results of nerve conduction examinations on the right median nerve. Further studies with more frequent electrophysiological assessment for more and predetermined nerves at predetermined time points over a longer time period could identify these features in greater detail and with greater confirmation. Third, as mentioned above, while pathogens of antecedent infections are associated with various clinical phenotypes in GBS, we did not perform the comprehensive test to identify pathogens of antecedent infection, such as serum antibody to $C$. jejuni. Fourth, the test for anti-ganglioside antibodies was performed; however, only antibodies against GM1 and GQ1b were assessed in a limited number of patients. Information about antibodies to a ganglioside complex consisting of GM1 and 
GalNAc-GD1a is especially important as the antibodies have been reported to be associated with a pure motor variant with RCF following respiratory infection.[36-38] Information about IgG subclass (IgG1 or IgG3) of anti-GM1 antibodies is also important because the IgG subclasses of AMAN-associated antibodies have been reported to be associated with antecedent infection and the speed of recovery of GBS.[39] However, these were not investigated in this study.

\section{Conclusions}

We showed that GBS patients with elevated CK levels represent a group of AMAN. Moreover, we showed that elevated CK tends to occur during the acute phase of AMAN following URTI. We also propose CK elevation to a candidate of the clinical features of GBS which differ between AMAN and AIDP. The presence of CK elevation could facilitate the accurate diagnosis of the disease subgroup.

\section{Abbreviations}

AIDP, acute inflammatory demyelinating polyneuropathy; AMAN, acute motor axonal neuropathy; CK, creatine kinase; CMAP, compound action potential; DML, distal motor latency; GBS, Guillain-Barré syndrome; IVIG, intravenous immunoglobulin; RCF, reversible conduction failure; M-AIDP, motor acute inflammatory demyelinating polyneuropathy; MS-AIDP, motor-sensory acute inflammatory demyelinating polyneuropathy; URTI, upper respiratory tract infection

\section{Declarations}

\section{Acknowledgment}

None.

\section{Authors' Contributors}

TH contributed to the conception and design, acquisition of data, analysis and interpretation of data and drafting of the manuscript. HN contributed to the concept and design, acquisition of data, analysis and interpretation of data and critical revision of the manuscript for important intellectual content. TS, YN, ES, AT, KU and SI contributed to acquisition of data. SS contributed to critical revision of the manuscript for important intellectual content. FK contributed to acquisition of data and critical revision of the manuscript for important intellectual content. SA contributed to critical revision of the manuscript for important intellectual content. All authors read and approved the final manuscript.

\section{Funding:}

This research did not receive any specific grant from funding agencies in the public, commercial, or not-for-profit sectors.

\section{Availability of data and materials}

The datasets used and/or analyzed during the current study are available from the corresponding author on reasonable request.

\section{Ethics approval and consent to participate}

All subjects gave their verbal informed consent prior to their inclusion in the study. Written consent to participate was waived as the present study was a retrospective observational study. This study was approved by the Ethics Committee of Osaka Medical College (No. 2074) and was conducted according to the principles expressed in the Declaration of Helsinki. 
Not applicable.

\section{Competing interests}

The authors declare that they have no competing interests.

\section{References}

1. Satoh J, Okada K, Kishi T, Nagayama S, Kuroda Y. Cramping pain and prolonged elevation of serum creatine kinase levels in a patient with Guillain-Barre syndrome following Campylobacter jejuni enteritis. Eur J Neurol. 2000;7 1:107-9.

2. Ho TW, Mishu B, Li CY, Gao CY, Cornblath DR, Griffin JW, et al. Guillain-Barre syndrome in northern China. Relationship to Campylobacter jejuni infection and anti-glycolipid antibodies. Brain. 1995;118 ( Pt 3):597-605.

3. Feasby TE, Gilbert JJ, Brown WF, Bolton CF, Hahn AF, Koopman WF, et al. An acute axonal form of Guillain-Barre polyneuropathy. Brain. 1986;109 ( Pt 6):1115-26.

4. McKhann GM, Cornblath DR, Griffin JW, Ho TW, Li CY, Jiang Z, et al. Acute motor axonal neuropathy: a frequent cause of acute flaccid paralysis in China. Ann Neurol. 1993;33 4:333-42.

5. Yuki N, Hartung HP. Guillain-Barre syndrome. N Engl J Med. 2012;366 24:2294-304.

6. Kuwabara S, Yuki N. Axonal Guillain-Barre syndrome: concepts and controversies. Lancet Neurol. 2013;12 12:1180-8; doi: 10.1016/S1474-4422(13)70215-1.

7. Yuki N, Taki T, Inagaki F, Kasama T, Takahashi M, Saito K, et al. A bacterium lipopolysaccharide that elicits Guillain-Barre syndrome has a GM1 ganglioside-like structure. J Exp Med. 1993;178 5:1771-5.

8. Kuwabara S, Yuki N, Koga M, Hattori T, Matsuura D, Miyake M, et al. IgG anti-GM1 antibody is associated with reversible conduction failure and axonal degeneration in Guillain-Barre syndrome. Ann Neurol. 1998;44 2:202-8.

9. Capasso M, Caporale CM, Pomilio F, Gandolfi P, Lugaresi A, Uncini A. Acute motor conduction block neuropathy Another GuillainBarre syndrome variant. Neurology. 2003;61 5:617-22.

10. Kuwabara S, Asahina M, Koga M, Mori M, Yuki N, Hattori T. Two patterns of clinical recovery in Guillain-Barre syndrome with IgG anti-GM1 antibody. Neurology. 1998;51 6:1656-60.

11. Kokubun N, Nishibayashi M, Uncini A, Odaka M, Hirata K, Yuki N. Conduction block in acute motor axonal neuropathy. Brain. 2010;133 10:2897-908.

12. Uncini A, Manzoli C, Notturno F, Capasso M. Pitfalls in electrodiagnosis of Guillain-Barre syndrome subtypes. J Neurol Neurosurg Psychiatry. 2010;81 10:1157-63.

13. Hiraga A, Kuwabara S, Ogawara K, Misawa S, Kanesaka T, Koga M, et al. Patterns and serial changes in electrodiagnostic abnormalities of axonal Guillain-Barre syndrome. Neurology. 2005;64 5:856-60.

14. Kuwabara S, Ogawara K, Misawa S, Koga M, Mori M, Hiraga A, et al. Does Campylobacter jejuni infection elicit "demyelinating" Guillain-Barre syndrome? Neurology. 2004;63 3:529-33.

15. Brown WF, Feasby TE. Conduction block and denervation in Guillain-Barre polyneuropathy. Brain. 1984;107 (Pt 1):219-39.

16. Baba M, Matsunaga M. Recovery from acute demyelinating conduction block in the presence of prolonged distal conduction delay due to peripheral nerve constriction. Electromyogr Clin Neurophysiol. 1984;24 7:611-7.

17. Clouston PD, Kiers L, Zuniga G, Cros D. Quantitative analysis of the compound muscle action potential in early acute inflammatory demyelinating polyneuropathy. Electroencephalogr Clin Neurophysiol. 1994;93 4:245-54.

18. Hosokawa T, Nakajima H, Unoda K, Yamane K, Doi Y, Ishida S, et al. An electrophysiological classification associated with GuillainBarre syndrome outcomes. J Neurol. 2014;261 10:1986-93.

19. Hosokawa T, Nakajima H, Unoda K, Yamane K, Doi Y, Ishida S, et al. Serial electrophysiological findings in Guillain-Barre syndrome not fulfilling AIDP or AMAN criteria. J Neurol. 2016;263 9:1709-18.

20. Asbury AK, Cornblath DR. Assessment of current diagnostic criteria for Guillain-Barre syndrome. Ann Neurol. 1990;27 Suppl:S21-4.

21. Yuki N, Kokubun N, Kuwabara S, Sekiguchi Y, Ito M, Odaka M, et al. Guillain-Barre syndrome associated with normal or exaggerated tendon reflexes. J Neurol. 2012;259 6:1181-90. 
22. Hughes RA, Newsom-Davis JM, Perkin GD, Pierce JM. Controlled trial prednisolone in acute polyneuropathy. Lancet. 1978;2 8093:750-3.

23. Lilleng H, Abeler K, Johnsen SH, Stensland E, Loseth S, Jorde R, et al. Variation of serum creatine kinase (CK) levels and prevalence of persistent hyperCKemia in a Norwegian normal population. The Tromso Study. Neuromuscul Disord. 2011;21 7:494-500.

24. Kimura J. electrodiagnosis in diseases of nerve and muscle: principles and practice. 2nd edn. Philadelphia: F.A. Davis; 1989.

25. Isose S, Kuwabara S, Kokubun N, Sato Y, Mori M, Shibuya K, et al. Utility of the distal compound muscle action potential duration for diagnosis of demyelinating neuropathies. J Peripher Nerv Syst. 2009;14 3:151-8.

26. Kalita J, Misra UK, Das M. Neurophysiological criteria in the diagnosis of different clinical types of Guillain-Barre syndrome. J Neurol Neurosurg Psychiatry. 2008;79 3:289-93.

27. Kuwabara S, Ogawara K, Mizobuchi K, Koga M, Mori M, Hattori T, et al. Isolated absence of F waves and proximal axonal dysfunction in Guillain-Barre syndrome with antiganglioside antibodies. J Neurol Neurosurg Psychiatry. 2000;68 2:191-5.

28. Feasby TE, Hahn AF, Brown WF, Bolton CF, Gilbert JJ, Koopman WJ. Severe axonal degeneration in acute Guillain-Barre syndrome: evidence of two different mechanisms? J Neurol Sci. 1993;116 2:185-92.

29. Griffin JW, Li CY, Ho TW, Tian M, Gao CY, Xue P, et al. Pathology of the motor-sensory axonal Guillain-Barre syndrome. Ann Neurol. 1996;39 1:17-28.

30. Scott AJ, Duncan R, Henderson L, Jamal GA, Kennedy PG. Acute rhabdomyolysis associated with atypical Guillain-Barre syndrome. Postgrad Med J. 1991;67 783:73-4.

31. Saxena A, Singh V, Verma N. Guillain-Barre syndrome complicated by acute fatal rhabdomyolysis. Indian J Crit Care Med. 2014;18 4:241-3.

32. Ropper AH, Shahani BT. Pain in Guillain-Barre syndrome. Arch Neurol. 1984;41 5:511-4.

33. Ho TW, Hsieh ST, Nachamkin I, Willison HJ, Sheikh K, Kiehlbauch J, et al. Motor nerve terminal degeneration provides a potential mechanism for rapid recovery in acute motor axonal neuropathy after Campylobacter infection. Neurology. 1997;48 3:717-24.

34. Kane NM, Oware A. Nerve conduction and electromyography studies. J Neurol. 2012;259 7:1502-8.

35. Mori M, Kuwabara S, Miyake M, Noda M, Kuroki H, Kanno H, et al. Haemophilus influenzae infection and Guillain-Barre syndrome. Brain. 2000;123 ( Pt 10):2171-8.

36. Ogawa G, Kaida K, Kuwahara M, Kimura F, Kamakura K, Kusunoki S. An antibody to the GM1/GalNAc-GD1a complex correlates with development of pure motor Guillain-Barre syndrome with reversible conduction failure. J Neuroimmunol. 2013;254 1-2:141-5.

37. Kaida K, Ariga T, Yu RK. Antiganglioside antibodies and their pathophysiological effects on Guillain-Barre syndrome and related disorders-a review. Glycobiology. 2009;19 7:676-92.

38. Kaida K, Sonoo M, Ogawa G, Kamakura K, Ueda-Sada M, Arita M, et al. GM1/GalNAc-GD1a complex: a target for pure motor Guillain-Barre syndrome. Neurology. 2008;71 21:1683-90.

39. Jacobs BC, Koga M, van Rijs W, Geleijns K, van Doorn PA, Willison HJ, et al. Subclass IgG to motor gangliosides related to infection and clinical course in Guillain-Barre syndrome. J Neuroimmunol. 2008;194 1-2:181-90.

\section{Tables}

Table 1 Clinical and laboratory features of 51 patients with GBS 


\begin{tabular}{|l|l|l|l|}
\hline & $\begin{array}{l}\text { GBS patients with elevated CK } \\
\text { levels } \\
(\mathrm{n}=14)\end{array}$ & $\begin{array}{l}\text { GBS patients with normal CK } \\
\text { levels } \\
(\mathrm{n}=37)\end{array}$ & $\begin{array}{l}P \text { - } \\
\text { value }\end{array}$ \\
\hline Age, years, mean \pm SD & $41.2 \pm 10.2$ & $47.7 \pm 21.1$ & NS \\
\hline Males, $\mathrm{n}(\%)$ & $12(86)$ & $19(51)$ & 0.029 \\
\hline Antecedent infection, $\mathrm{n}(\%)$ & $13(93)$ & $22(59)$ & 0.039 \\
\hline Gastroenteritis, $\mathrm{n}(\%)$ & $5(35)$ & $14(38)$ & NS \\
\hline $\begin{array}{l}\text { Upper respiratory tract infection, } \mathrm{n} \\
(\%)\end{array}$ & $8(57)$ & $8(21)$ & 0.021 \\
\hline Clinical symptoms & & & \\
\hline Hypoesthesia, $\mathrm{n}(\%)$ & $1(7)$ & $15(41)$ & 0.039 \\
\hline Cranial nerve involvement, $\mathrm{n}(\%)$ & $2(14)$ & $19(51)$ & 0.025 \\
\hline Ophthalmoparesis & $1(7)$ & $7(19)$ & NS \\
\hline Facial palsy & $1(7)$ & $10(27)$ & NS \\
\hline Oropharyngeal palsy & $2(14)$ & $17(46)$ & NS \\
\hline Urinary retention, $\mathrm{n}(\%)$ & $0(0)$ & $12(32)$ & 0.022 \\
\hline Preserved tendon reflexes, $\mathrm{n}(\%)$ & $9(64)$ & $16(43)$ & NS \\
\hline Anti-GM1 antibody, $\mathrm{n}(\%)$ & $8 / 12(67)$ & $8 / 32(25)$ & 0.016 \\
\hline Hughes grade at peak & & & NS \\
\hline 1 & $1(7)$ & $3(8)$ & \\
\hline 2 & $7(50)$ & $13(35)$ & \\
\hline 3 & $2(14)$ & $4(11)$ & \\
\hline 4 & $3(21)$ & $13(35)$ & $3(8)$ \\
\hline 5 & $1(7)$ & $1(3)$ & \\
\hline 6 & $0(0)$ & & \\
\hline
\end{tabular}

Abbreviations: GBS, Guillain-Barré syndrome; CK, creatine kinase; NS, not significant

Table 2 Electrophysiological features of the initial nerve conduction examinations of 51 GBS patients 


\begin{tabular}{|c|c|c|c|}
\hline & $\begin{array}{l}\text { GBS patients with elevated CK } \\
\text { levels } \\
(\mathrm{n}=14)\end{array}$ & $\begin{array}{l}\text { GBS patients with normal CK } \\
\text { levels } \\
(\mathrm{n}=37)\end{array}$ & $\begin{array}{l}P \text { - } \\
\text { value }\end{array}$ \\
\hline \multicolumn{4}{|l|}{ Electrodiagnosis } \\
\hline- & - & - & - \\
\hline - & - & - & - \\
\hline- & - & - & - \\
\hline \multirow[t]{2}{*}{-} & - & - & - \\
\hline & - & - & - \\
\hline AIDP pattern & $8(57)$ & $22(59)$ & NS \\
\hline AMAN pattern & $3(21)$ & $5(14)$ & NS \\
\hline Unclassified & $3(21)$ & $10(27)$ & NS \\
\hline $\begin{array}{l}\text { Sensory nerve conduction } \\
\text { abnormality }\end{array}$ & $0(0)$ & $16(43)$ & 0.002 \\
\hline Absence of $F$ waves & $5(35)$ & $13(35)$ & NS \\
\hline
\end{tabular}

Abbreviations: GBS, Guillain-Barré syndrome; CK, creatine kinase; AIDP, acute inflammatory demyelinating polyneuropathy; AMAN, acute motor axonal neuropathy; NS, not significant

Table 3 Subgroups of 51 GBS patients

\begin{tabular}{|l|l|l|l|}
\hline & $\begin{array}{l}\text { GBS patients with elevated CK } \\
\text { levels } \\
(\mathrm{n}=14)\end{array}$ & $\begin{array}{l}\text { GBS patients with normal CK } \\
\text { levels } \\
(\mathrm{n}=37)\end{array}$ & $\begin{array}{l}P \text { - } \\
\text { value }\end{array}$ \\
\hline AIDP & $0(0)$ & $15(41)$ & 0.005 \\
\hline AMAN & $14(100)$ & $22(59)$ & 0.005 \\
\hline $\begin{array}{l}\text { AMAN with axonal } \\
\text { degeneration }\end{array}$ & $3(21)$ & $5(14)$ & NS \\
\hline AMAN with RCF & $11(79)$ & $17(46)$ & NS \\
\hline
\end{tabular}

Abbreviations: GBS, Guillain-Barré syndrome; CK, creatine kinase; AIDP, acute inflammatory demyelinating polyneuropathy; AMAN, acute motor axonal neuropathy; RCF, reversible conduction failure; NS, not significant

Table 4 CK levels and clinical features of 14 patients with Guillain-Barré syndrome with elevated CK levels 


\begin{tabular}{|c|c|c|c|c|c|c|c|c|c|c|c|c|c|c|}
\hline \multirow{2}{*}{$\begin{array}{l}\text { Patient } \\
\text { No. }\end{array}$} & \multirow[t]{2}{*}{ Age/sex } & \multicolumn{3}{|l|}{ CK } & \multirow{2}{*}{$\begin{array}{l}\text { Cranial nerve } \\
\text { involvement }\end{array}$} & \multicolumn{3}{|c|}{ Limb weakness } & \multirow{2}{*}{$\begin{array}{l}\text { CMAP } \\
\text { amplitude } \\
(\mathrm{mV}) \\
\text { Right } \\
\text { median } \\
\text { nerve }\end{array}$} & \multirow[t]{2}{*}{ Treatment } & \multicolumn{4}{|c|}{ Disability } \\
\hline & & $\begin{array}{l}\text { Time } \\
\text { until } \\
\text { first } \\
\text { elevation } \\
\text { (days) }\end{array}$ & $\begin{array}{l}\text { Time } \\
\text { until } \\
\text { peak } \\
\text { (days) }\end{array}$ & $\begin{array}{l}\text { Level } \\
\text { at } \\
\text { peak } \\
(\mathrm{U} / \mathrm{L})\end{array}$ & & $\begin{array}{l}\text { Arm or leg } \\
\text { dominant }\end{array}$ & $\begin{array}{l}\text { Proximal } \\
\text { or distal } \\
\text { dominant }\end{array}$ & $\begin{array}{l}\text { Symmetric } \\
\text { or } \\
\text { asymmetric }\end{array}$ & & & $\begin{array}{l}\text { Time } \\
\text { until } \\
\text { nadir } \\
\text { (days) }\end{array}$ & $\begin{array}{l}\text { At } \\
\text { nadir } \\
\text { (HG) }\end{array}$ & $\begin{array}{l}\begin{array}{l}14 \\
\text { days }\end{array} \\
\text { after } \\
\text { onset } \\
\text { (HG) }\end{array}$ & $\begin{array}{l}28 \\
\text { days } \\
\text { after } \\
\text { onset } \\
\text { (HG) }\end{array}$ \\
\hline 1 & $\begin{array}{l}20- \\
29 / \mathrm{M}\end{array}$ & 4 & 4 & 1937 & None & $\begin{array}{l}\text { Arm } \\
\text { dominant }\end{array}$ & $\begin{array}{l}\text { Distal } \\
\text { dominant }\end{array}$ & Symmetric & 0.5 & IVIG & 4 & 2 & 1 & 1 \\
\hline 2 & $\begin{array}{l}30- \\
39 / \mathrm{M}\end{array}$ & 9 & 9 & 1264 & None & $\begin{array}{l}\text { No } \\
\text { dominance }\end{array}$ & $\begin{array}{l}\text { No } \\
\text { dominance }\end{array}$ & Symmetric & 6.2 & IVIG & 2 & 3 & 2 & 1 \\
\hline 3 & $\begin{array}{l}30- \\
39 / \mathrm{M}\end{array}$ & 11 & 11 & 795 & None & $\begin{array}{l}\text { Arm } \\
\text { dominant }\end{array}$ & $\begin{array}{l}\text { Distal } \\
\text { dominant }\end{array}$ & Symmetric & 3.2 & IVIG & 11 & 2 & 2 & 1 \\
\hline 4 & $\begin{array}{l}20- \\
29 / \mathrm{M}\end{array}$ & 16 & 24 & 591 & None & $\begin{array}{l}\text { No } \\
\text { dominance }\end{array}$ & $\begin{array}{l}\text { No } \\
\text { dominance }\end{array}$ & Symmetric & 7.1 & IVIG & 15 & 2 & 2 & 1 \\
\hline 5 & $\begin{array}{l}30- \\
39 / \mathrm{M}\end{array}$ & 11 & 14 & 550 & $\begin{array}{l}\text { Ophthalmoplegia, } \\
\text { Facial weakness, } \\
\text { bulbar weakness }\end{array}$ & $\begin{array}{l}\text { No } \\
\text { dominance }\end{array}$ & $\begin{array}{l}\text { Distal } \\
\text { dominant }\end{array}$ & Symmetric & 7 & $\begin{array}{l}\text { IVIG } \square \\
\text { steroid } \\
\text { pulse }\end{array}$ & 4 & 4 & 2 & 2 \\
\hline 6 & $\begin{array}{l}40- \\
49 / \mathrm{M}\end{array}$ & 2 & 10 & 515 & None & $\begin{array}{l}\text { Arm } \\
\text { dominant }\end{array}$ & $\begin{array}{l}\text { Distal } \\
\text { dominant }\end{array}$ & Symmetric & 2.5 & IVIG & 4 & 2 & 2 & 2 \\
\hline 7 & $\begin{array}{l}30- \\
39 / \mathrm{M}\end{array}$ & 9 & 9 & 433 & None & $\begin{array}{l}\text { Arm } \\
\text { dominant }\end{array}$ & $\begin{array}{l}\text { Distal } \\
\text { dominant }\end{array}$ & Symmetric & 5.2 & None & 6 & 2 & 2 & 0 \\
\hline 8 & $\begin{array}{l}30- \\
39 / \mathrm{M}\end{array}$ & 25 & 28 & 429 & Bulbar weakness & $\begin{array}{l}\text { Leg } \\
\text { dominant }\end{array}$ & $\begin{array}{l}\text { No } \\
\text { dominance }\end{array}$ & Symmetric & 0.5 & $\begin{array}{l}\text { IVIG } \square \\
\text { plasma } \\
\text { exchange }\end{array}$ & 10 & 5 & 5 & 5 \\
\hline 9 & $\begin{array}{l}50- \\
59 / \mathrm{M}\end{array}$ & 7 & 7 & 402 & None & $\begin{array}{l}\text { Arm } \\
\text { dominant }\end{array}$ & $\begin{array}{l}\text { No } \\
\text { dominance }\end{array}$ & Asymmetric & 7.5 & IVIG & 12 & 1 & 1 & 1 \\
\hline 10 & $\begin{array}{l}50- \\
59 / \mathrm{M}\end{array}$ & 2 & 4 & 396 & None & $\begin{array}{l}\text { No } \\
\text { dominance }\end{array}$ & $\begin{array}{l}\text { Distal } \\
\text { dominant }\end{array}$ & Asymmetric & 7 & IVIG & 5 & 4 & 1 & 1 \\
\hline 11 & $40-49 / \mathrm{F}$ & 6 & 10 & 351 & None & $\begin{array}{l}\text { No } \\
\text { dominance }\end{array}$ & $\begin{array}{l}\text { No } \\
\text { dominance }\end{array}$ & Symmetric & 7.8 & IVIG & 8 & 2 & 1 & 1 \\
\hline 12 & $\begin{array}{l}40- \\
49 / \mathrm{M}\end{array}$ & 3 & 5 & 319 & None & $\begin{array}{l}\text { No } \\
\text { dominance }\end{array}$ & $\begin{array}{l}\text { No } \\
\text { dominance }\end{array}$ & Symmetric & 8.8 & IVIG & 4 & 2 & 2 & 1 \\
\hline 13 & $\begin{array}{l}40- \\
49 / \mathrm{M}\end{array}$ & 10 & 16 & 300 & None & $\begin{array}{l}\text { No } \\
\text { dominance }\end{array}$ & $\begin{array}{l}\text { No } \\
\text { dominance }\end{array}$ & Symmetric & 2.5 & IVIG & 4 & 4 & 3 & 2 \\
\hline 14 & $60-69 / \mathrm{F}$ & 5 & 5 & 288 & None & $\begin{array}{l}\text { No } \\
\text { dominance }\end{array}$ & \begin{tabular}{|l} 
Distal \\
dominant
\end{tabular} & Symmetric & 7.5 & IVIG & 4 & 3 & 2 & 1 \\
\hline
\end{tabular}

To anonymize the identifying information, specific ages were grouped into age ranges.

Abbreviations: CK, creatine kinase; CMAP, compound action potential; HG, Hugh grade;IVIG, intravenous immunoglobulin

Figures 


\section{GBS with elevated CK levels}
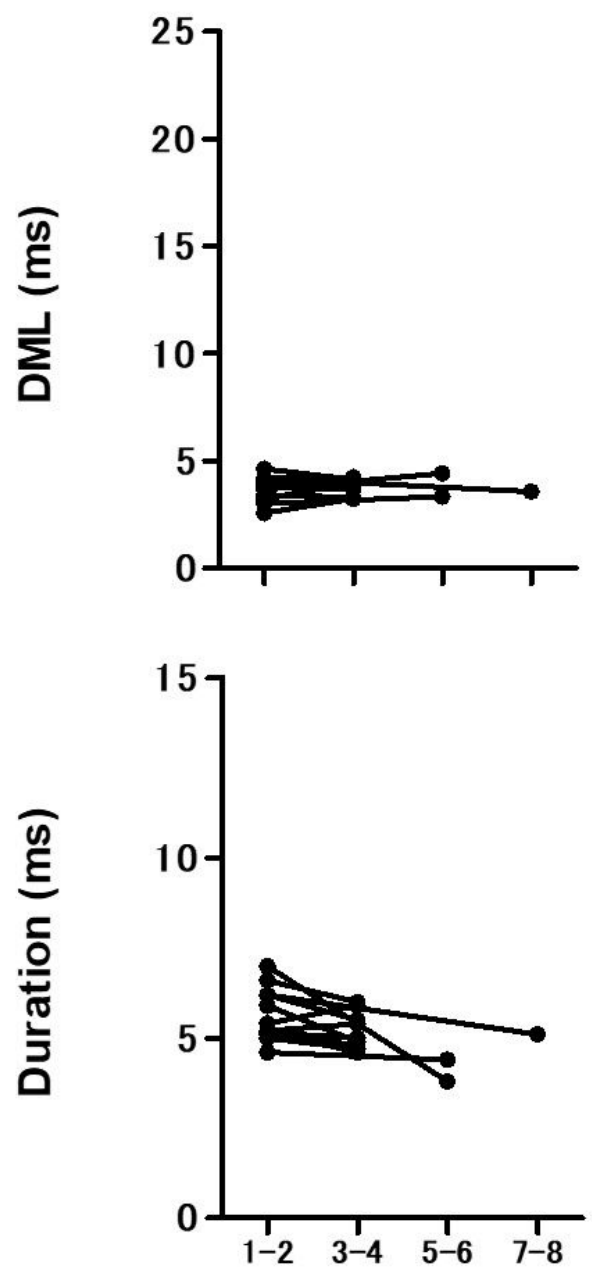

Time after onset (weeks)

\section{GBS with normal CK levels}
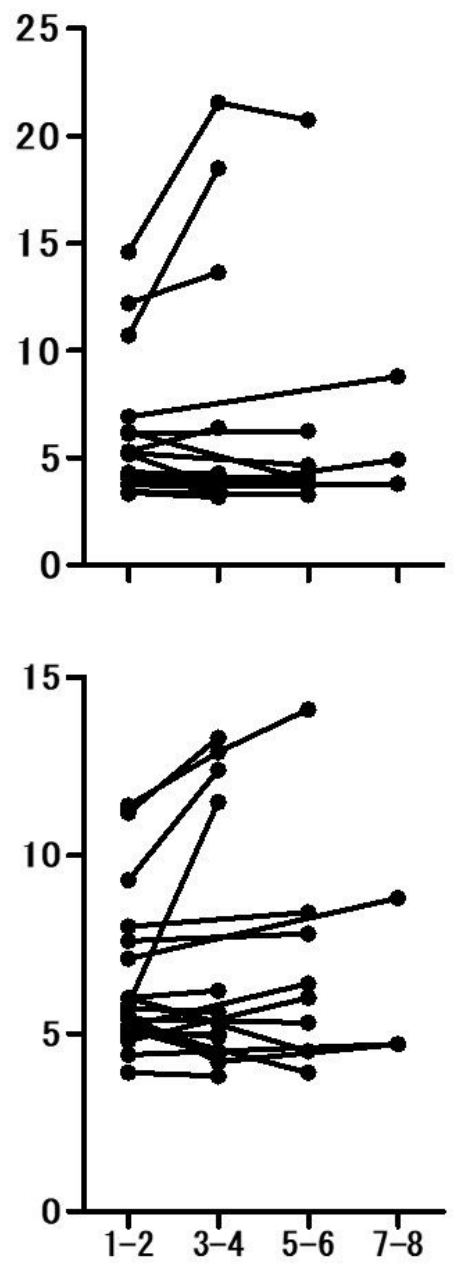

Time after onset (weeks)

\section{Figure 1}

Serial findings of DML and duration in the right median motor nerve of GBS patients with and without elevated CK levels GBS, GuillainBarré syndrome; $\mathrm{CK}$, creatine kinase; $\mathrm{DML}$, distal motor latency 